\title{
Oxidation of Mandelic Acid by Os(VIII)
}

\author{
B. L. Chandwani and G. D. Menghani \\ Chemical Laboratories, University of Jodhpur, Jodhpur, India
}

Z. Naturforsch. 33 b, 291-292 (1978); received September 29, 1976/August 26/December 2, 1977

Mandelic Acid, Osmium(VIII)

In the reaction between mandelic acid and Os(VIII), the rate of Os(VIII) disappearance was found to be proportional to the concentration of mandelate ion and Os(VIII). At low and high hydroxyl ion concentration the rate shows second and zero order dependence respectively. The reaction was studied at different temperatures and various activation parameters $\triangle \mathrm{E}, \mathrm{PZ}, \Delta \mathrm{S}^{*}$ etc. were evaluated.

Kinetic studies on the oxidation of a variety of substances both organic and inorganic [1, 4-7] reveal extensive use of $\mathrm{Os}(\mathrm{VIII})$ as catalyst. Little evidence, however, is available on the vigour of $\mathrm{Os}(\mathrm{VIII})$ as an independent oxidant $[3,8,9]$. Therefore, oxidation of glycolic, lactic, mandelic, malic acids by $\mathrm{Os}(\mathrm{VIII})$ was investigated and the present report deals with the oxidation of mandelic acid by $\mathrm{Os}(\mathrm{VIII})$.

\section{Experimental}

$\mathrm{OsO}_{4}$ (Johnson \& Mathey) and mandelic acid Riedle A. R. were used. All other reagents were of A. R. grade. The reaction was started by mixing the alkaline solution of $\mathrm{OsO}_{4}$ and mandelic acid, maintained at constant temperature in a thermostat, regulated by electronic relay with an accuracy of $\pm 0.1^{\circ} \mathrm{C}$. The kinetics of the reactions were followed colorimetrically using Klett-Summerson photoelectric colorimeter and employing a blue light filter No. 42.

\section{Results}

The results summarised in Table I-III show dependence of the rate on [mandelate], [Os(VIII)], $\left[\mathrm{OH}^{-}\right]$. Increase in ionic strength as a result of addition of $\mathrm{KNO}_{3}$ or $\mathrm{K}_{2} \mathrm{SO}_{4}$ increases the rate of oxidation (Table IV). Addition of sulphuric acid at constant $\left[\mathrm{SO}_{4}{ }^{2-}\right.$ ] decreases the rate of oxidation, but further addition of acid does not change the rate significantly.

\section{Stoichiometry}

Number of reaction mixtures containing excess of Os(VIII) were thermostated at $35^{\circ} \mathrm{C}$ for $1-4 \mathrm{~h}$. A known volume was withdrawn from each reaction

Requests for reprints should be sent to Dr. B. L. Chandwani, Department of Chemistry, University of Jodhpur, India.
Table I. Effect of varying the oxidant concentration.

\begin{tabular}{ll}
$\begin{array}{c}{\left[\begin{array}{c}\text { mandelate }]=5.0 \times 10^{-3} \mathrm{M} \\
{\left[\mathrm{OH}^{-}\right]=.012 \mathrm{M}}\end{array}\right.} \\
{\left[\mathrm{OsO}_{4}\right] \times 10^{4} \mathrm{M}}\end{array}$ & temp. $35^{\circ} \mathrm{C}$ \\
\hline 5.0 & $\mathrm{~K}_{1} \times 10^{4} \mathrm{sec}^{-1}$ \\
4.0 & 7.1 \\
3.0 & 7.0 \\
2.0 & 6.9 \\
1.0 & 6.8 \\
\hline
\end{tabular}

Table II. Effect of varying the reductant concentration.

$\left[\mathrm{OsO}_{4}\right]=5.0 \times 10^{-4} \mathrm{M} \quad$ temp. $35^{\circ} \mathrm{C}$.
$\left[\mathrm{OH}^{-}\right]=.012 \mathrm{M}$

\begin{tabular}{lll}
\hline [mandelate] $\times 10^{3} \mathrm{M}$ & $\mathrm{K}_{1} \times 10^{4} \mathrm{sec}^{-1}$ & $\frac{\mathrm{K}_{1}}{[\text { mandelate] }}$ \\
& & mole $\mathrm{sec}^{-1}$ \\
\hline 5.0 & 7.1 & 0.14 \\
4.0 & 5.2 & 0.13 \\
3.0 & 4.5 & 0.15 \\
2.0 & 2.8 & 0.14 \\
1.0 & 1.5 & 0.15 \\
\hline
\end{tabular}

Table III. Effect of varying the alkali concentration.

\begin{tabular}{lc}
{$\left[\mathrm{OsO}_{4}\right]=5.0 \times 10^{-4} \mathrm{M} \begin{array}{r}\text { [mandelate }] \\
\text { temp. } 35^{\circ} \mathrm{C} . \mu\end{array}=\mathbf{1 . 0}$} \\
\hline$\left[\mathrm{OH}^{-}\right] \times 10^{2} \mathrm{M}$ & $\mathrm{K}_{1} \times 10^{3} \mathrm{sec}^{-1}$ \\
\hline 1.2 & 0.71 \\
1.6 & 1.20 \\
2.0 & 2.0 \\
3.0 & 4.30 \\
4.0 & 4.28 \\
6.0 & 4.31 \\
20.0 & 4.30 \\
\hline
\end{tabular}

mixture and analysed colorimetrically for unconsumed Os(VIII). Two moles of Os(VIII) are required for each mole of reductant. Benzoic acid 
Table IV. Effect of varying the ionic strength.

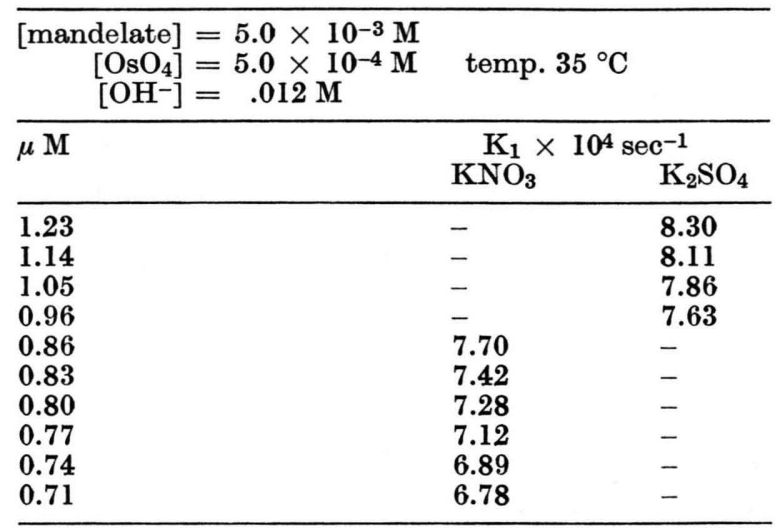

Table V. Effect of varying $\mathrm{H}^{+}$concentration.

\begin{tabular}{|c|c|}
\hline $\begin{aligned}\text { mandelate }] & =5.0 \times 10^{-3} \mathrm{M} \\
{\left[\mathrm{OH}^{-}\right] } & =.012 \mathrm{M}\end{aligned}$ & $\begin{array}{l}{\left[\mathrm{OsO}_{4}\right]=5.0 \times 10^{-4} \mathrm{M}} \\
{\left[\mathrm{SO}_{4}^{2-}\right]=.5 \mathrm{M}} \\
\text { temp. } 35{ }^{\circ} \mathrm{C}\end{array}$ \\
\hline$\left[\mathrm{H}^{+}\right] \times \mathrm{M}$ & $\mathrm{K}_{1} \times 10^{4} \mathrm{sec}^{-1}$ \\
\hline $\begin{array}{l}0.1 \\
0.08 \\
0.06 \\
0.04 \\
0.02\end{array}$ & $\begin{array}{l}7.3 \\
7.4 \\
7.6 \\
7.9 \\
8.0\end{array}$ \\
\hline
\end{tabular}

was identified to be the main reaction product in the samples after complete reduction of $\mathrm{Os}$ (VIII).

\section{Discussion}

The possibility of a free radical mechanism is excluded on the grounds that the reaction involves a two electron change, does not show an induction period and the rate of reaction is unaffected by addition of acrylonitrile. The alkali dependence of rate of reaction indicates that mandelate ions are the entities oxidised. In view of the fact that $\mathrm{OsO}_{4}$ in alkaline solution coordinates with $\mathrm{OH}^{-}$and occurs as osmate ion [2], it is suggested that oxidation of mandelic acid involves formation of ester intermediate and its subsequent rapid cleavage into products. The $\left[\mathrm{OsO}_{4} \mathrm{OH}\right]^{3-}$ species is hydrated to
$\left[\mathrm{OsO}_{2}(\mathrm{OH})_{4}\right]^{2-}$, this is fully supported by the fact [2] that $\mathrm{Os}(\mathrm{VIII})$ conclusively exists as $\left[\mathrm{OsO}_{2}(\mathrm{OH})_{4}\right]^{2-}$ species.

$$
\begin{aligned}
& \mathrm{K}_{1} \\
& \mathrm{OsO}_{4}+2 \mathrm{OH}^{-} \underset{\mathrm{K}-1}{\stackrel{\mathrm{K}_{1}}{\rightleftharpoons}}\left[\mathrm{OsO}_{4}(\mathrm{OH})_{2}\right]^{2-} \\
& \stackrel{\mathrm{C}_{6} \mathrm{H}_{5}}{\stackrel{\mathrm{CHOHCO}}{ }}+\left[\mathrm{OsO}_{4}(\mathrm{OH})_{2}\right]^{2-} \underset{\mathrm{K}_{2}}{\stackrel{\text { slow }}{\longrightarrow}} \\
& {\left[\begin{array}{l}
\mathrm{C}_{6} \mathrm{H}_{5} \\
\stackrel{\mathrm{I}}{\mathrm{CHOOSO}}{ }_{4} \mathrm{OH} \\
\stackrel{\mathrm{I}}{\mathrm{COO}}{ }^{-}
\end{array}\right]^{2-}+\mathrm{H}_{2} \mathrm{O}} \\
& {\left[\begin{array}{l}
\mathrm{C}_{6} \mathrm{H}_{5} \\
\stackrel{\mathrm{I}}{\mathrm{CHOO} \mathrm{SO}_{4} \mathrm{OH}} \\
\stackrel{\mathrm{COO}}{-}
\end{array}\right]^{2-} \rightarrow} \\
& \mathrm{C}_{6} \mathrm{H}_{5} \mathrm{CHO}+\mathrm{CO}_{2}+\left[\mathrm{OsO}_{4} \mathrm{OH}\right]^{3-} \\
& {\left[\mathrm{OsO}_{4} \mathrm{OH}\right]^{3-}+2 \mathrm{H}_{2} \mathrm{O} \rightarrow} \\
& {\left[\mathrm{OsO}_{2}(\mathrm{OH})_{4}\right]^{2-}+\mathrm{OH}^{-}}
\end{aligned}
$$

Applying steady state approximation, the rate of disappearance of $\mathrm{Os}(\mathrm{VIII})$ is given by:

$$
\left.\frac{-\mathrm{d}[\mathrm{Os}(\mathrm{VIII})]}{\mathrm{dt}}=\mathrm{K}_{2} \text { [mandelate }\right][\mathrm{Os}(\mathrm{VIII})]
$$

This explains first order dependence of rate on mandelate and [Os(VIII)]. According to equation (1) the concentration of active oxidant species $\left[\mathrm{OsO}_{4}(\mathrm{OH})_{2}\right]^{2-}$ would depend on $\left[\mathrm{OH}^{-}\right]^{2}$ upto a limit, beyond that whole of $\mathrm{OsO}_{4}$ will exist as $\left[\mathrm{OsO}_{4}(\mathrm{OH})_{2}\right]^{2-}$, this explaines second and zero-order dependence of the rate on $\left[\mathrm{OH}^{-}\right]$at low and high hydroxyl ion concentration respectively.

The activation parameters $\triangle \mathrm{E}, \mathrm{PZ}, \Delta \mathrm{S}^{*}$ were evaluated and found to be $5.6 \mathrm{kcal}, 2.6 \times 10^{3} \mathrm{sec}^{-1}$ and $-43.7 \mathrm{E}$. U. respectively. More negative value of $\triangle \mathrm{S}^{*}$ and positive salt effect lend further support to the rate determining step.
[1] M. C. Agarwal and S. P. Mushran, J. Phys. Chem. 72, 1497 (1968).

[2] F. A. Cotton and G. Wilkonson, Adv. Inorg. Chem. 1962, 830.

[3] S. P. Mushran, Can. J. Chem. 48, 1148 (1970).

[4] V. N. Singh and M. P. Singh, Aust. J. Chem. 21, 2913 (1968).
[5] V. N. Singh and M. P. Singh, Aust. J. Chem. 23, 921 (1970).

[6] G. C. Soni and G. D. Menghani, Tetrahedron 28, 5567 (1972).

[7] G. C. Soni and G. D. Menghani, Z. Naturforsch. 27 b, 908 (1972).

[8] N. L. Wendler, J. Am. Chem. Soc. 72, 234 (1950).

[9] T. Rayon, Tetrahedron Lett. 1964, 2259. 